\title{
Understanding a mechanism of organic co-solvent inactivation in heme monooxygenase P450 BM-3
}

Jochen Kuper, ${ }^{\dagger}$ Tuck Seng Wong, ${ }^{\star}$ Danilo Roccatano, ${ }^{\dagger}$ Matthias Wilmanns, ${ }^{\dagger}$ and Ulrich Schwaneberg ${ }^{*}$,

${ }^{\dagger}$ EMBL-Hamburg Outstation, DESY, Hamburg, Germany, and ${ }^{\ddagger}$ Jacobs University

Bremen, School of Engineering and Science, Campus Ring 1, 28759 Bremen,

Germany.

\section{Supporting Information}

\section{Materials and methods}

\subsection{General methods}

All chemicals used were of analytical reagent grade or higher quality and purchased from Sigma-Aldrich Chemie (Taufkirchen, Germany), Applichem (Darmstadt, Germany) and Carl Roth (Karlsruhe, Germany).

A thermal cycler (Mastercycler gradient; Eppendorf, Hamburg, Germany) and thinwall PCR tubes (M $\mu$ lti-Ultra tubes; $0.2 \mathrm{~mL}$; Carl Roth, Germany) were used in all PCRs. The PCR volume was always $50 \mu \mathrm{L}$; larger volumes were prepared in multiple $50 \mu \mathrm{L}$ PCRs. The amount of DNA was quantified using a NanoDrop photometer (NanoDrop Technologies, Wilmington, Delaware, USA). All PCR purification and gel extraction were performed using QIAquick PCR purification kit (Qiagen, Düren, Germany) and QIAquick gel extraction kit (Qiagen) respectively. Enzymes were purchased from New England Biolabs (Frankfurt, Germany), unless otherwise stated.

\subsection{Cloning of P450 BM-3 heme domain (BMP) into pETM-11 vector}

Gene segment encoding P450 BM-3 heme domain (BMP, Thr1-Leu455) was amplified from pCWori vector ${ }^{1}$ harboring full-length $\mathrm{P} 450 \mathrm{BM}-3$ gene (encoding both heme and reductase domains). For the PCR $\left(95^{\circ} \mathrm{C}\right.$ for $30 \mathrm{~s}, 1$ cycle; $95^{\circ} \mathrm{C}$ for 30 $\mathrm{s} / 55^{\circ} \mathrm{C}$ for $1 \mathrm{~min} / 68^{\circ} \mathrm{C}$ for $2 \mathrm{~min}, 30$ cycles; $68^{\circ} \mathrm{C}$ for $10 \mathrm{~min}, 1$ cycle), $2.5 \mathrm{U} \mathrm{Pfu}$ Turbo DNA polymerase (Stratagene Europe, Amsterdam Zuidoost, Netherlands), 0.2 $\mathrm{mM}$ dNTP mix (New England Biolabs), 20 pmol of each primer (5'[Phos]CATGACAATTAAAGAAATGCCTC-3', and 5'CTGGAATTCTTAAAGCGGAATTTTTTTCGATTT-3') and 100 ng template (pCWori vector harboring P450 BM-3 gene) were used. The PCR product was subsequently ligated into pETM-11 vector using NcoI and EcoRI restriction sites, followed by transformation into $E$. coli XL2 Blue (Stratagene) using TSS method. ${ }^{2}$

\subsection{Expression of P450 BM-3 heme domain (BMP) in shaking flask}

pETM-11 vector harboring P450 BM-3 heme domain gene was freshly transformed into $E$. coli BL21 (DE3). Single colony was picked to prepare overnight culture in 5 $\mathrm{mL} \mathrm{LB}_{\text {kan }}$ media. Three hundred $\mathrm{mL} \mathrm{TB}_{\text {kan }}$ media, supplemented with $300 \mu \mathrm{L}$ trace element $\left(0.5 \mathrm{~g} \mathrm{CaCl}_{2} \cdot 2 \mathrm{H}_{2} \mathrm{O}, 0.18 \mathrm{~g} \mathrm{ZnSO}_{4} \cdot 7 \mathrm{H}_{2} \mathrm{O}, 0.10 \mathrm{~g} \mathrm{MnSO}_{4} \cdot \mathrm{H}_{2} \mathrm{O}, 20.1 \mathrm{~g} \mathrm{Na}_{2}-\right.$ EDTA, $16.7 \mathrm{~g} \mathrm{FeCl}_{3} \cdot 6 \mathrm{H}_{2} \mathrm{O}, 0.16 \mathrm{~g} \mathrm{CuSO}_{4} \cdot 5 \mathrm{H}_{2} \mathrm{O}, 0.18 \mathrm{~g} \mathrm{CoCl}_{2} \cdot 6 \mathrm{H}_{2} \mathrm{O}$, add $1 \mathrm{~L} \mathrm{H}_{2} \mathrm{O}$ and autoclave), were inoculated with $1.5 \mathrm{~mL}$ overnight culture. The culture was incubated $\left(37^{\circ} \mathrm{C}, 250 \mathrm{rpm}, \sim 3 \mathrm{~h}\right.$; Multitron II; Infors GmbH, Einsbach, Germany) and

\footnotetext{
* To whom correspondence addressed: u.schwaneberg@iu-bremen.de
} 
expression was induced by adding $\delta$-aminolevulinic acid anhydride (ALA, $0.5 \mathrm{mM}$ ) and isopropyl- $\beta$-D-thiogalactoside (IPTG, $100 \mu \mathrm{M}$ ) when $\mathrm{OD}_{600}$ reached 0.5-0.6. After cultivation of $\sim 12 \mathrm{~h}\left(30^{\circ} \mathrm{C}, 200 \mathrm{rpm}\right.$; Multitron II; Infors $)$, the cells were harvested by centrifugation and pellets were stored at $-20{ }^{\circ} \mathrm{C}$ for further use.

\subsection{Purification of P450 BM-3 heme domain (BMP)}

Purification of polyhistidine-tagged P450 BM-3 heme domain was performed using Protino Ni-IDA 2000 packed column (Macherey-Nagel, Düren, Germany) according to instructions given in manufacturer's manual. Imidazole was removed using PD-10 desalting column (Amersham Biosciences Europe GmbH, Freiburg, Germany). Histag was cleaved from the N-terminal of P450 BM-3 heme domain using AcTEV protease (Invitrogen $\mathrm{GmbH}$, Karlsruhe, Germany). AcTEV protease was subsequently removed by loading the reaction mixture onto a Protino Ni-IDA 2000 packed column (Macherey-Nagel). Finally, P450 BM-3 heme domain was subjected to size-exclusion chromatography (Matrix: Toyoperl HW-55S, Bed volume: $30 \mathrm{~mL}$, Bed height: $40 \mathrm{~cm}$, Column: Omnifit). Collected fractions were concentrated to $\sim 30 \mathrm{mg} / \mathrm{ml}$ using an Amicon Ultra-4 centrifugal filter (Millipore, Schwalbach, Germany). Protein concentration was determined by $\mathrm{CO}$-difference spectra, as reported by Omura and Sato, ${ }^{3}$ using $\varepsilon=91 \mathrm{mM}^{-1} \mathrm{~cm}^{-1}$.

\subsection{UV-vis spectroscopic measurement}

UV-vis spectroscopy was performed on Specord 200 (Analytik Jena, Jena, Germany) using glass cuvettes (Type 108-OS; Hellma GmbH \& Co. KG, Müllheim, Germany). Spectra of $\mathrm{P} 450 \mathrm{BM}-3$ heme domain (final concentration $\sim 1 \mu \mathrm{M}$ ) were measured in buffer $\left(150 \mathrm{mM} \mathrm{NaH}_{2} \mathrm{PO}_{4}\right.$, pH 7.0), in 1ow DMSO concentration $\left(150 \mathrm{mM} \mathrm{NaH}_{2} \mathrm{PO}_{4}\right.$, $\mathrm{pH} 7.0,14 \%(\mathrm{v} / \mathrm{v}) \mathrm{DMSO})$ and in high DMSO concentration $\left(150 \mathrm{mM} \mathrm{NaH}_{2} \mathrm{PO}_{4}, \mathrm{pH}\right.$ $7.0,30 \%(\mathrm{v} / \mathrm{v}) \mathrm{DMSO})$. Absorbance was recorded from 300 to $650 \mathrm{~nm}$, at a speed of $1 \mathrm{~nm} / \mathrm{s}$ and delta lambda of $0.1 \mathrm{~nm}$.

\subsection{Crystallization of P450 BM-3 heme domain (BMP)}

A) P450 BM-3 heme domain in low DMSO concentration (Lo-DMSO): Crystallization conditions were screened using high-throughput crystallization facility at EMBL/DESY, Hamburg, Germany. Protein sample was prepared by adding $14 \%$ $(\mathrm{v} / \mathrm{v})$ DMSO into P450 BM-3 heme domain protein solution $(\sim 30 \mathrm{mg} / \mathrm{ml}$ in $50 \mathrm{mM}$ $\mathrm{NaH}_{2} \mathrm{PO}_{4}, \mathrm{pH}$ 7.5). Crystallization trials were carried out using sitting-drop vapor diffusion in 96-well microtiter plate (CrystalQuick LBR; Greiner Bio-One GmbH, Frickenhausen, Germany) with a drop size of $600 \mathrm{~nL}(300 \mathrm{~nL}$ protein sample +300 $\mathrm{nL}$ mother liquor). In total, 480 conditions (Index, SaltRx, PEG/Ion screen, Crystal Screen, Crystal Screen 2, Crystal Screen Lite, Crystal Screen Cryo, Natrix; Hampton Research, California, USA) were tested at both $5^{\circ} \mathrm{C}$ and $19^{\circ} \mathrm{C}$. Needle-shaped crystals were obtained in $0.05 \mathrm{M}$ zinc acetate, $20 \%(\mathrm{w} / \mathrm{v})$ PEG3350 at $5^{\circ} \mathrm{C}$. Crystals were subjected to data collection after one week at $5^{\circ} \mathrm{C}$. B) P450 BM-3 heme domain in high DMSO concentration (Hi-DMSO): Protein sample was prepared by adding $14 \%$ $(\mathrm{v} / \mathrm{v})$ DMSO into P450 BM-3 heme domain protein solution $(\sim 30 \mathrm{mg} / \mathrm{ml}$ in $50 \mathrm{mM}$ $\mathrm{NaH}_{2} \mathrm{PO}_{4}, \mathrm{pH}$ 7.5). Crystallization trials were carried out using vapor diffusion in hanging-drop plate (EasyXtal Tool; Qiagen) with a drop size of $4 \mu \mathrm{L}$ ( $2 \mu \mathrm{L}$ protein sample $+2 \mu \mathrm{L}$ mother liquor). Needle-shaped crystals were obtained in $0.04 \mathrm{M}$ zinc acetate, $15 \%(\mathrm{w} / \mathrm{v})$ PEG3350, $14 \%(\mathrm{v} / \mathrm{v})$ DMSO at $5^{\circ} \mathrm{C}$. Crystals were subjected to data collection after one week at $5^{\circ} \mathrm{C}$. Crystallization conditions are summarized in Table S1. 


\begin{tabular}{|c|c|c|}
\hline & \begin{tabular}{|c|} 
Lo-DMSO \\
\end{tabular} & Hi-DMSO \\
\hline Method & $\begin{array}{l}\text { Sitting-drop vapor diffusion in 96- } \\
\text { well microtiter plate (CrystalQuick } \\
\text { LBR; Greiner Bio-One GmbH) }\end{array}$ & $\begin{array}{l}\text { Hanging-drop vapor diffusion in } \\
\text { 24-well plate (EasyXtal Tool; } \\
\text { Qiagen) }\end{array}$ \\
\hline Protein sample & $\begin{array}{l}30 \mathrm{mg} / \mathrm{ml} \text { protein in phosphate } \\
\text { buffer }\left(50 \mathrm{mM} \mathrm{NaH} \mathrm{PO}_{4}, \mathrm{pH}\right. \\
7.5) \text { to which } 14 \%(\mathrm{v} / \mathrm{v}) \text { DMSO } \\
\text { was added }\end{array}$ & $\begin{array}{l}30 \mathrm{mg} / \mathrm{ml} \text { protein in phosphate } \\
\text { buffer }\left(50 \mathrm{mM} \mathrm{NaH} \mathrm{PO}_{4}, \mathrm{pH}\right. \\
7.5) \text { to which } 14 \%(\mathrm{v} / \mathrm{v}) \text { DMSO } \\
\text { was added }\end{array}$ \\
\hline Mother liquor & $\begin{array}{l}0.05 \mathrm{M} \text { zinc acetate, } 20 \%(\mathrm{w} / \mathrm{v}) \\
\text { PEG3350 }\end{array}$ & $\begin{array}{l}0.04 \mathrm{M} \text { zinc acetate, } 15 \%(\mathrm{w} / \mathrm{v}) \\
\text { PEG3350, } 14 \%(\mathrm{v} / \mathrm{v}) \mathrm{DMSO}\end{array}$ \\
\hline Drop size & $\begin{array}{l}600 \mathrm{~nL}(300 \mathrm{~nL} \text { protein sample } \\
+300 \mathrm{~nL} \text { mother liquor) }\end{array}$ & $\begin{array}{l}4 \mu \mathrm{l}(2 \mu \mathrm{L} \text { protein sample }+2 \\
\mu \mathrm{L} \text { mother liquor })\end{array}$ \\
\hline Crystallization temperature & $5^{\circ} \mathrm{C}$ & $5^{\circ} \mathrm{C}$ \\
\hline Diffraction & $\begin{array}{l}\text { Crystal subjected to data } \\
\text { collection after } 1 \text { week at } 5^{\circ} \mathrm{C}\end{array}$ & $\begin{array}{l}\text { Crystal subjected to data } \\
\text { collection after } 1 \text { week at } 5^{\circ} \mathrm{C}\end{array}$ \\
\hline
\end{tabular}

Table S1: Summary of crystallization conditions.

All crystallization experiments were carried out as vapor diffusion equilibrium experiments. After a drop mixing event, the BMP and the buffer contents were halved in their concentrations. During equilibration with the mother liquor, the drop size is reduced by half and the concentration of the content is doubled. Assuming that DMSO (vapour pressure $0.55 \mathrm{mbar} @ 20^{\circ} \mathrm{C}$; boiling point $189^{\circ} \mathrm{C}$ ) is not or to a small extent volatile at these concentrations, the DMSO concentration reached during crystallization values that are given in Table $\mathrm{S} 1$ or close to those values. Concentration differences between Lo- and Hi- DMSO were always $\sim$ two-folds.

\subsection{Data collection and refinement}

X-ray data were collected on flash-cooled crystals up to $2.1 \AA$ at beamline X13 (LoDMSO) and up to $1.7 \AA$ at beamline BW7A (Hi-DMSO) at EMBL/DESY. Mother liquor, to which $25 \%(\mathrm{v} / \mathrm{v})$ glycerol was added, was used as a cryoprotectant. Data were indexed with MOSFLM ${ }^{4}$ and processed with SCALA $^{5}$ from the CCP4 suite. ${ }^{6}$ The initial phases were obtained from molecular replacement using PHASER $^{7}$ and using Protein Data Bank (PDB) entry $1 B U 7^{8}$ as a search model. The structure was refined by alternating rounds of manual model building in $\mathrm{COOT}^{9}$ and refinement with REFMAC. ${ }^{10}$ Atomic coordinates and structure factors have been deposited in the PDB as entries 2J4S (Lo-DMSO) and 2J1M (Hi-DMSO). Data collection and refinement statistics are summarized in Table S2. 


\begin{tabular}{|c|c|c|}
\hline & Lo-DMSO & Hi-DMSO \\
\hline Space group & $\mathrm{P} 2_{1} 2_{1} 2_{1}$ & $\mathrm{P} 2_{1} 2_{1} 2_{1}$ \\
\hline Cell dimension $(\AA)$ & $\begin{array}{lll}79.6 & 88.3 & 151.3\end{array}$ & $\begin{array}{lll}81.8 & 86.8 & 159.4\end{array}$ \\
\hline No. of independent reflections & 62273 & 125177 \\
\hline Data range $(\AA)$ & $23.48-2.09$ & $38.35-1.7$ \\
\hline \multicolumn{3}{|l|}{$R_{\text {merge }}(\%)$} \\
\hline Overall & 12 & 7.7 \\
\hline Last shell & 45 & 71 \\
\hline \multicolumn{3}{|l|}{ Data completeness $(\%)$} \\
\hline Overall & 97.4 & 100.0 \\
\hline Last shell & 83.7 & 100.0 \\
\hline \multicolumn{3}{|l|}{$I /(\sigma) I$} \\
\hline Overall & 9.3 & 15.3 \\
\hline Last shell & 2.0 & 2.3 \\
\hline \multicolumn{3}{|l|}{ Redundancy } \\
\hline Overall & 3.5 & 6.6 \\
\hline Last shell & 3.2 & 6.5 \\
\hline $\begin{array}{l}\text { No. of reflections used in the } \\
\text { refinements }\end{array}$ & $59066(21.78-2.1)$ & $118744(36.04-1.70)$ \\
\hline No. of non-H protein atoms & 7289 & 7377 \\
\hline No. of water molecules & 455 & 955 \\
\hline$R_{\text {work }}(\%)$ & 19.3 & 16.9 \\
\hline$R_{\text {free }}(\%)$ & 24.4 & 19.9 \\
\hline RMSD in bond lengths $(\AA)$ & 0.014 & 0.016 \\
\hline RMSD in bond angles $\left(^{\circ}\right)$ & 1.555 & 1.512 \\
\hline \multicolumn{3}{|l|}{ Mean $B$ value $\left(\AA^{2}\right)$} \\
\hline protein & 27.5 & 28 \\
\hline hetatoms & 30.6 & 39.9 \\
\hline \multirow[t]{2}{*}{ Missing residues } & Pro243-Thr245 (chain A) & Thr1 (chain A) \\
\hline & Pro243-Glu247 (chain B) & Thr1 (chain B) \\
\hline $\mathrm{RMSD} \mathrm{C}_{\alpha}$, mol A vs mol B $(\AA)$ & 0.376 & 0.468 \\
\hline
\end{tabular}

Table S2: Summary of refinement statistics.

\subsection{Expression and purification of full-length P450 BM-3}

Full-length P450 BM-3 was expressed and purified as described. ${ }^{11,12}$ In brief, P450 BM-3 was cloned behind the double tac promoter of the expression vector pCWori. ${ }^{1}$ E. coli XL2 Blue (Stratagene), transformed with pCWori_BM3, was used for expression of P450 BM-3 in 250-mL scale. P450 BM-3 was purified using ion exchange chromatography, as reported previously by Schwaneberg et al. ${ }^{11}$ P450 BM3's concentration was determined by CO-difference spectra, as reported by Omura and Sato, ${ }^{3}$ using $\varepsilon=91 \mathrm{mM}^{-1} \mathrm{~cm}^{-1}$.

\subsection{Photometric enzyme assay}

Activity of full-length P450 BM-3 was measured in various concentrations of DMSO ( 5 to $30 \%(\mathrm{v} / \mathrm{v}))$ using 12-pNCA assay as described previously by Schwaneberg et al. ${ }^{13,14}$ All photometric assays were carried out at ambient temperature under aerobic condition. UV-vis spectrophotometer (Specord 200; Analytik Jena) and cuvettes (1.5$\mathrm{mL}$ semi-micro PMMA Plastibrand; Brand, Wertheim, Germany) were used in all kinetic measurements. A reaction mixture contained $875-\mathrm{x} \mu \mathrm{L}$ Tris/ $\mathrm{HCl}$ buffer $(100$ $\mathrm{mM}, \mathrm{pH}$ 8.1), $\mathrm{x} \mu \mathrm{L}$ DMSO (Fluka; 41640; Assay $\geq 99.9 \%$ (GC)), $5 \mu \mathrm{L}$ pnitrododecanoic acid (12-pNCA; $15 \mathrm{mM}$; dissolved in DMSO) and $20 \mu \mathrm{L}$ purified protein solution $(9 \mu \mathrm{M})$. Reactions were initiated after a 10 -min incubation time by the addition of $100 \mu \mathrm{L}$ NADPH $(10 \mathrm{mM})$. Rate of hydroxylation was recorded at 410 $\mathrm{nm}$ for $5 \mathrm{~min}$. 


\section{Results and discussions}

\subsection{DMSO tolerance profile of P450 BM-3}

Purified P450 BM-3 (BM3) retains $\sim 70 \%$ of its activity at $14 \%$ (v/v) DMSO. Activity drops drastically to $\sim 10 \%$ when DMSO concentration reaches $28 \%(\mathrm{v} / \mathrm{v})$ (Figure S1). ${ }^{15}$

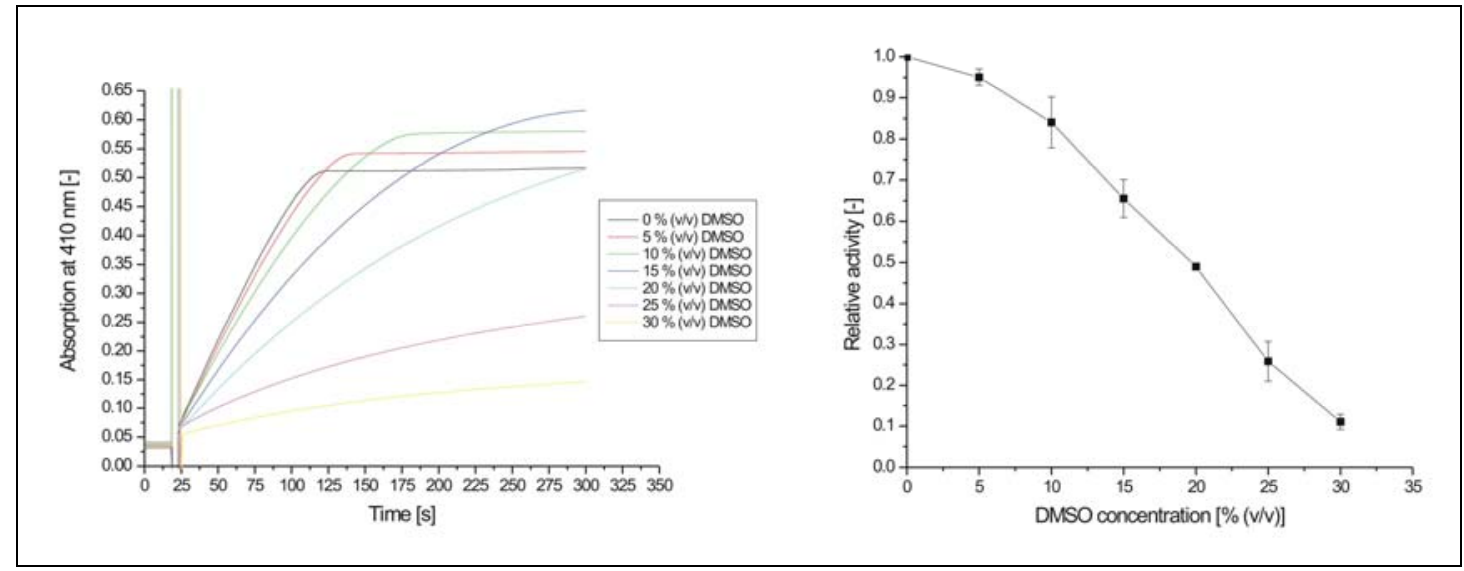

Figure S1: P450 BM-3 kinetic measurements in various concentrations of DMSO using 12-pNCA assay $^{13,14}$ (left) and DMSO tolerance profile of highly purified P450 BM-3 (right).

\subsection{Overall structures of Lo-DMSO and Hi-DMSO}

Comparisons of BMP crystal structures in low and high DMSO concentrations $\{(14$ $\%(\mathrm{v} / \mathrm{v})$; resolution $2.1 \AA$; Lo-DMSO) // $(28 \%(\mathrm{v} / \mathrm{v})$; resolution $1.7 \AA$; Hi-DMSO $)\}$ to a previous BM3 structure (1BU7) ${ }^{8}$ show similar overall folds without a sign of partial or global unfolding, as predicted by $\mathrm{MD}^{16,17}$ and confirmed by UV-vis measurements (Table S3, Figure S2 and S3). In Figures S4 and S5, root mean square deviations of each residue in Lo-DMSO and Hi-DMSO are reported, in comparison to 1BU7. Figure S6 reports the average B-factors of every residue in Lo-DMSO, Hi-DMSO and $1 B U 7$.

\begin{tabular}{|lccc|}
\hline & Monomer A & Monomer B & Average \\
\hline Lo-DMSO & & & \\
vs 1BU7 monomer A & $0.75 \AA$ & $0.85 \AA$ & $0.80 \AA$ \\
vs 1BU7 monomer B & $0.60 \AA$ & $0.60 \AA$ & $0.60 \AA$ \\
Hi-DMSO & & & \\
vs 1BU7 monomer A & $0.55 \AA$ & $0.45 \AA$ & $0.50 \AA$ \\
vs 1BU7 monomer B & $1.06 \AA$ & $1.02 \AA$ & $1.04 \AA$ \\
\hline
\end{tabular}

Table S3: Comparison of Lo-DMSO and Hi-DMSO to 1BU7. Average root mean square deviations are reported and values are calculated using GROMACS. ${ }^{18}$ 

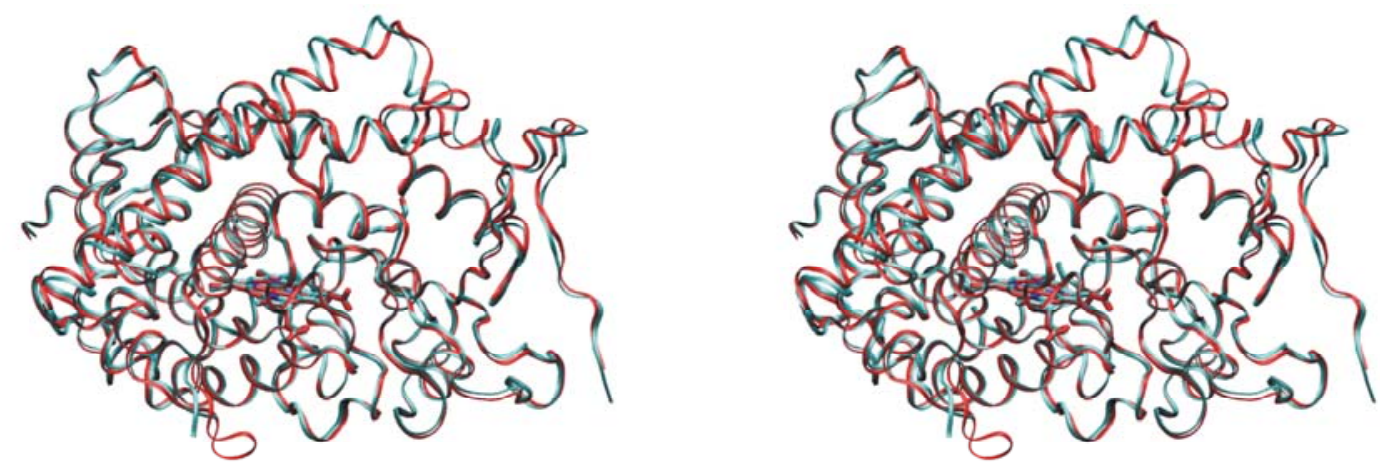

Figure S2: Stereo view of structure overlap of Lo-DMSO (cyan) and 1BU7 (red). Picture is created using VMD. ${ }^{19}$

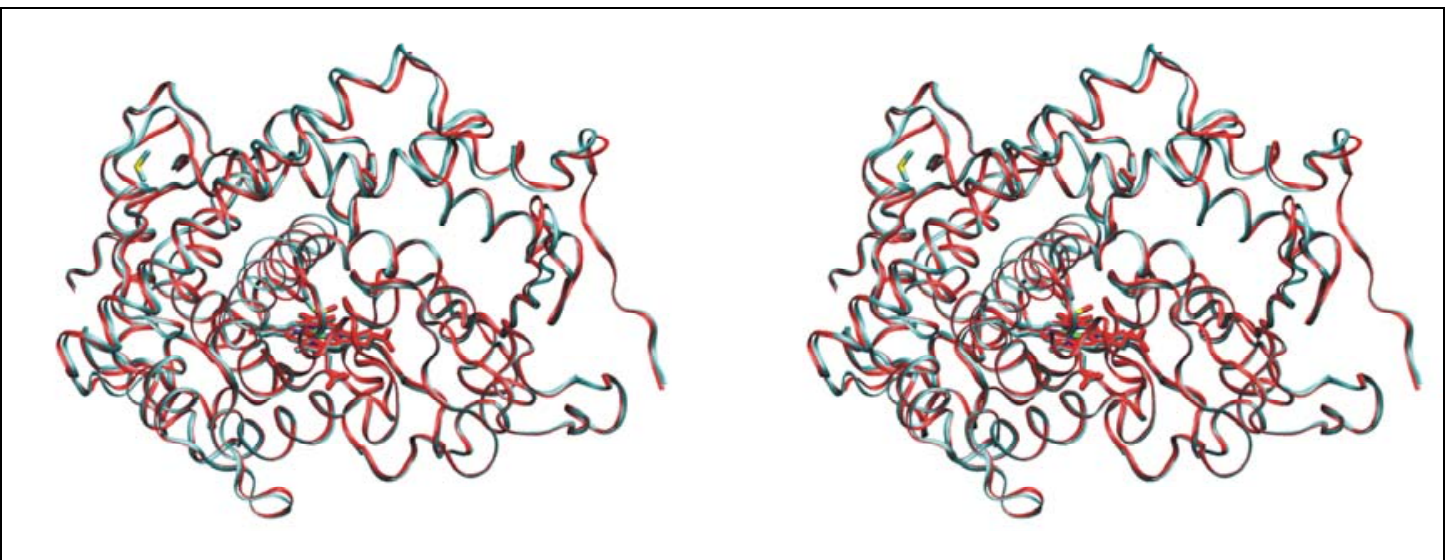

Figure S3: Stereo view of structure overlap of Hi-DMSO (cyan) and 1BU7 (red). DMSO located on BMP surface is shown in licorice. Picture is created using VMD. ${ }^{19}$ 


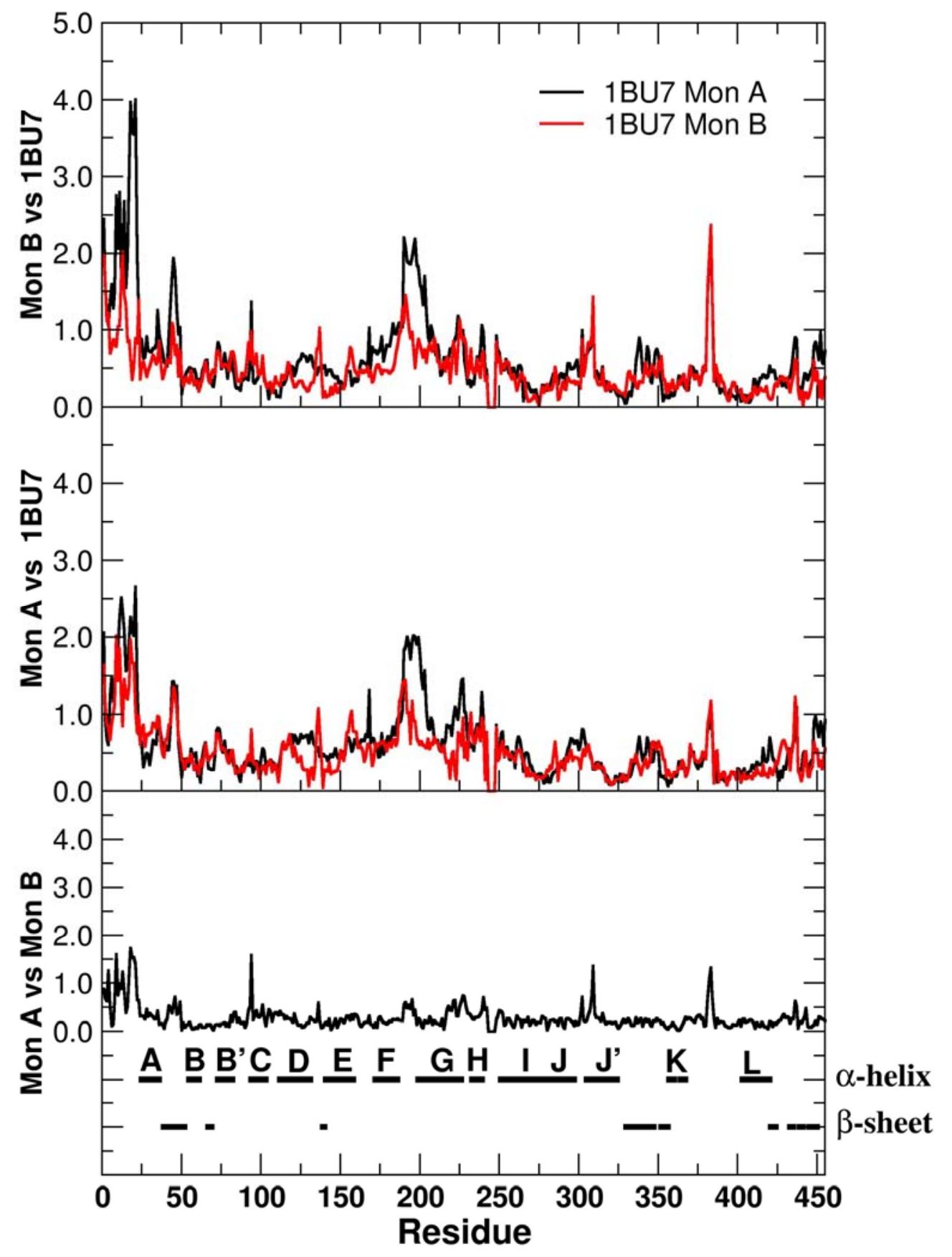

Figure S4: Root mean square deviations of each residue in Lo-DMSO using 1BU7 as reference structure. Values are calculated using GROMACS. ${ }^{18}$ 


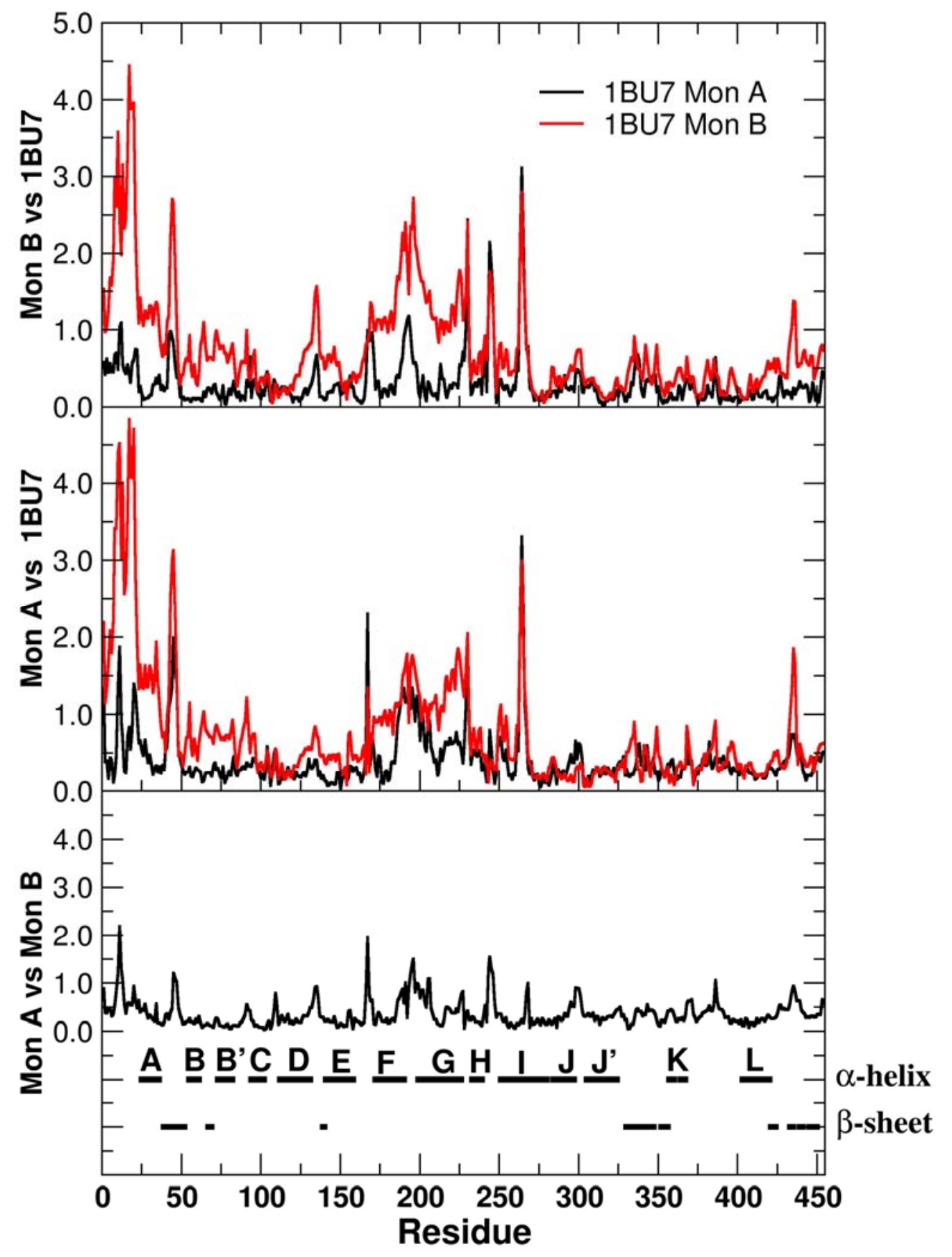

Figure S5: Root mean square deviations of each residue in Hi-DMSO using 1BU7 as reference structure. Values are calculated using GROMACS. ${ }^{18}$ 


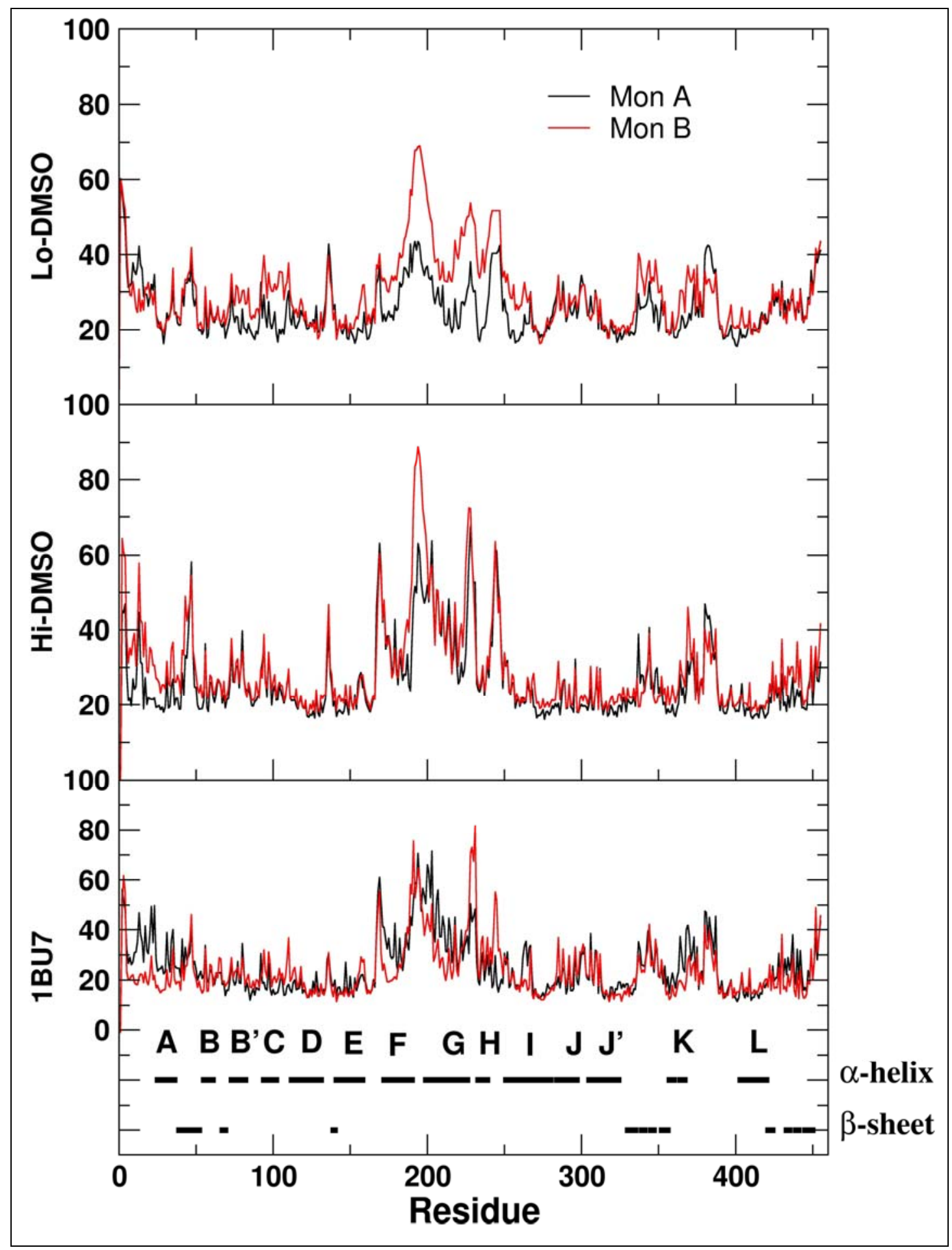

Figure S6: Average B-factors of every residue in Lo-DMSO, Hi-DMSO and 1BU7. 


\subsection{Opening of substrate channel leading to the heme}

The two monomers in the asymmetric unit of 1BU7 showed large structural differences in the substrate channel entry. ${ }^{8}$ Compared to monomer A, monomer B has a more opened substrate binding channel ${ }^{8}$ which contributes to the high RMSD between both monomers in 1BU7. ${ }^{8}$ In Lo- and Hi-DMSO, we observe high B-factors in the amino acids flanking the substrate access channel: R47 (involved in substrate orientation by interacting with carbonyl group of fatty acid $^{20}$ ), F helix (H171-R190), G helix (A197-S226) and F/G loop (A191-P196). Our crystallographic findings are in agreement with previous MD studies ${ }^{16,17}$ in solutions which support high flexibility of BMP's substrate binding pocket. Interestingly, the previously specified regions show large conformational changes upon substrate binding in the substrate-bound and substrate-free structures solved by Poulos and coworkers. ${ }^{21}$ Crystallographic data from Lo-/Hi-DMSO also suggests that substrate channel of BMP is highly dynamic and previous MD studies ${ }^{17}$ indicated even a DMSO-induced substrate channel opening (defined by distances P45-A191 and R47-Y51; Tables S4 and S5, Figure S7).

\begin{tabular}{|lccc|}
\hline & Monomer A & Monomer B & Average \\
\hline P45 Ca- A191 Ca & & & \\
1BU7 & $8.42 \AA$ & $11.24 \AA$ & $9.83 \AA$ \\
Lo-DMSO & $9.52 \AA$ & $9.78 \AA$ & $9.65 \AA$ \\
Hi-DMSO & $11.00 \AA$ & $9.96 \AA$ & $10.48 \AA$ \\
R47 Ca- Y51 Ca & & & \\
1BU7 & $13.13 \AA$ & $13.35 \AA$ & $13.24 \AA$ \\
Lo-DMSO & $12.92 \AA$ & $12.87 \AA$ & $12.90 \AA$ \\
Hi-DMSO & $12.96 \AA$ & $13.19 \AA$ & $13.08 \AA$ \\
\hline
\end{tabular}

Table S4: Distances between P45-A191 pair and R47-Y51 pair.

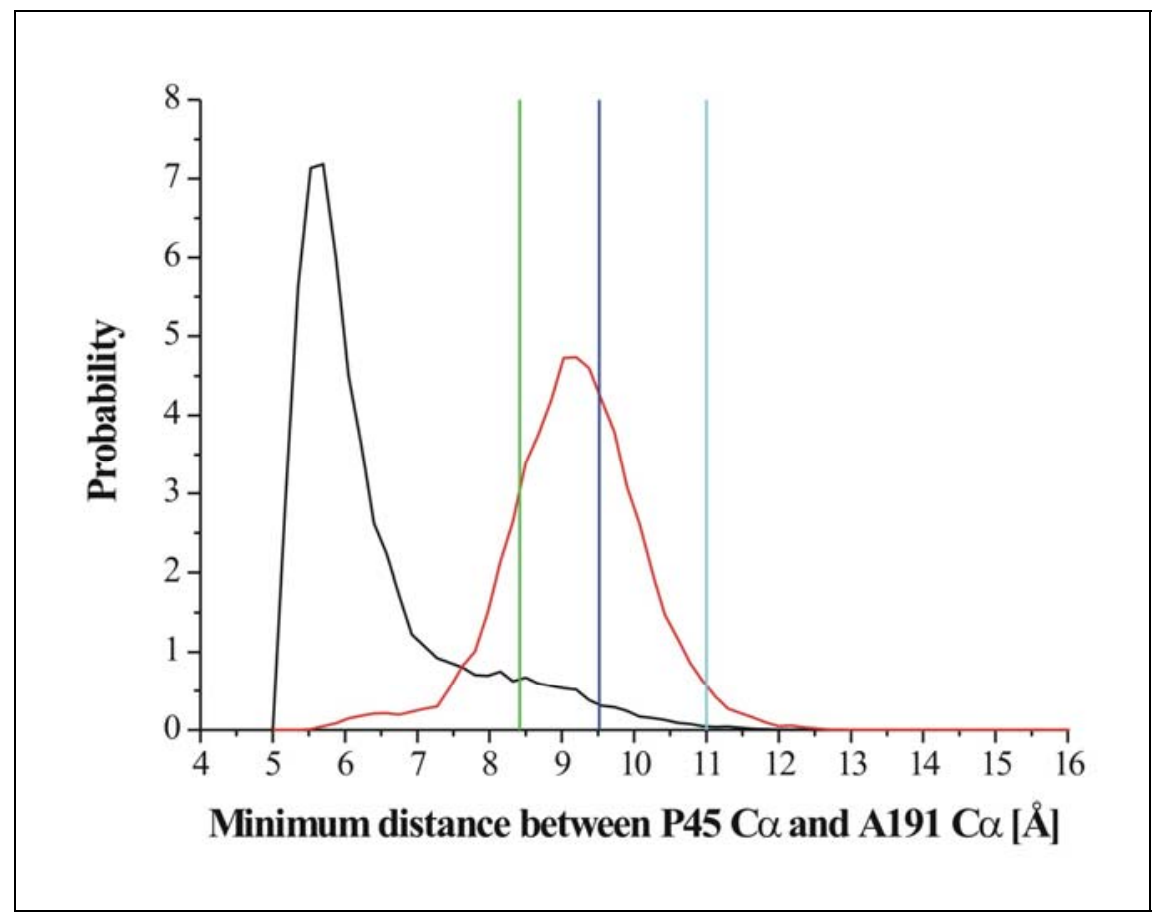

Figure S7: Opening of substrate channel leading to the heme. Black curve and red curve represent MD simulations of BMP in water and in $14 \%(\mathrm{v} / \mathrm{v}) \mathrm{DMSO}^{16,17}$, respectively. Vertical lines indicate $\mathrm{P} 45 \mathrm{C} \alpha$ - A191 Ca distances in 1BU7 monomer A (green), Lo-DMSO monomer A (blue) and Hi-DMSO monomer A (cyan). 
1BU7

Monomer A

Monomer B

Average

Lo-DMSO

Monomer A

Monomer B

Average

Hi-DMSO

Monomer A

Monomer B

Average
$7.25 \AA$

$6.27 \AA$

$6.76 \AA$

$7.41 \AA$

$4.14 \AA$

$5.78 \AA$

$13.96 \AA^{*}$
$6.36 \AA^{*}$
$10.16 \AA$

$12.13 \AA *$

$6.59 \AA *$

$9.36 \AA$

$9.72 \AA$

$10.60 \AA$

$7.69 \AA$

$9.47 \AA$

$10.16 \AA$

*The large difference between these values is due to different orientation of R47's side chain. In Lo-DMSO (monomer A) and Hi-DMSO (monomers A and B), the side chain of R47 is pointing towards Q73 presumably due to an electrostatic interaction. In 1BU7 (monomers A and B) and Lo-DMSO (monomer B), R47's side chain is pointing to Y51. The high fluctuation of R47 residue was also observed in our previous MD simulation. ${ }^{16}$ The results from our crystallographic data are in agreement with other crystallographic data that evidences high mobility of this residue. ${ }^{22}$

Table S5: Distances between BMP residues Y51 (OH) to R47 (NH1) and Y51 (OH) to R47 (NH2). 


\subsection{Heme coordination}

The most striking difference between Lo-DMSO and Hi-DMSO lies in the heme coordination (Figure S8, S9 and S10). In Lo-DMSO, a slight nonplanar distortion of the heme is observed compared to 1BU7 in which the iron is displaced distally by $\sim 0.16 \AA$ on average (Table S7). Furthermore, the water molecule coordinated to the heme iron is displaced aside (towards A328). Distances between irons and coordinated water molecules $\left(\mathrm{Fe}-\mathrm{O}_{\text {Water }}\right)$ are $3.56 \AA$ for $\mathrm{H}_{2} \mathrm{O} 239$ (monomer $\mathrm{A}$ ) and $3.97 \AA$ for $\mathrm{H}_{2} \mathrm{O} 207$ (monomer B) (Table S8, Figure S8 and S10). In 1BU7, a water molecule is heme-coordinated at its $6^{\text {th }}$ position with an average distance of $2.63 \AA$ (Table S8, Figure S8). In Hi-DMSO, a DMSO molecule is found to coordinate surprisingly the heme iron at its $6^{\text {th }}$ position via a sulfur atom $\left(\mathrm{Fe}-\mathrm{S}_{\mathrm{DMSO}}\right.$ distances are $2.35 \AA$ and $2.39 \AA$ for monomers A and B respectively; Table S8, Figure S9 and S10). These covalent $\mathrm{Fe}-\mathrm{S}_{\mathrm{DMSO}}$ bonds have almost identical distances of $5^{\text {th }} \mathrm{C} 400$ ligand in the heme center (average Fe-S $\mathrm{S}_{\mathrm{Cys} 400}$ distance $2.33 \AA$; Table S8). One methyl group of DMSO tethers to F87 (distance $3.7 \AA$ ) while the other one points to T268.

\begin{tabular}{|lccc|} 
& Monomer A & Monomer B & Average \\
\hline Lo-DMSO & $17.5 \AA^{2}$ & $19.0 \AA^{2}$ & $18.3 \AA^{2}$ \\
Hi-DMSO & $20.0 \AA^{2}$ & $19.7 \AA^{2}$ & $19.9 \AA^{2}$ \\
1BU7 & $13.0 \AA^{2}$ & $16.1 \AA^{2}$ & $14.6 \AA^{2}$ \\
\hline
\end{tabular}

Table S6: Average B-factors of hemes in Lo-DMSO, Hi-DMSO and $1 \mathrm{BU} 7$.

\begin{tabular}{|lcc||}
\hline & \multicolumn{3}{c|}{ Lo-DMSO } \\
\hline 1BU7 & Monomer A & Monomer B \\
Monomer A & $0.089 \AA(0.200 \AA)$ & $0.087 \AA(0.123 \AA)$ \\
& $0.074 \AA(0.194 \AA)$ & $0.067 \AA(0.131 \AA)$ \\
\hline 1BU7 & & Hi-DMSO \\
Monomer A & Monomer A & Monomer B \\
Monomer B & $0.095 \AA(0.030 \AA)$ & $0.097 \AA(0.045 \AA)$ \\
& $0.085 \AA(0.030 \AA)$ & $0.085 \AA(0.045 \AA)$ \\
\hline Lo-DMSO & & Hi-DMSO \\
Monomer A & Monomer A & Monomer B \\
Monomer B & $0.054 \AA(0.207 \AA)$ & $0.042 \AA(0.152 \AA)$ \\
\hline
\end{tabular}

Table S7: Root mean square deviations of porphyrin rings of BMP, calculated using GROMACS. ${ }^{18}$ Values in brackets represent distances between corresponding heme irons. 


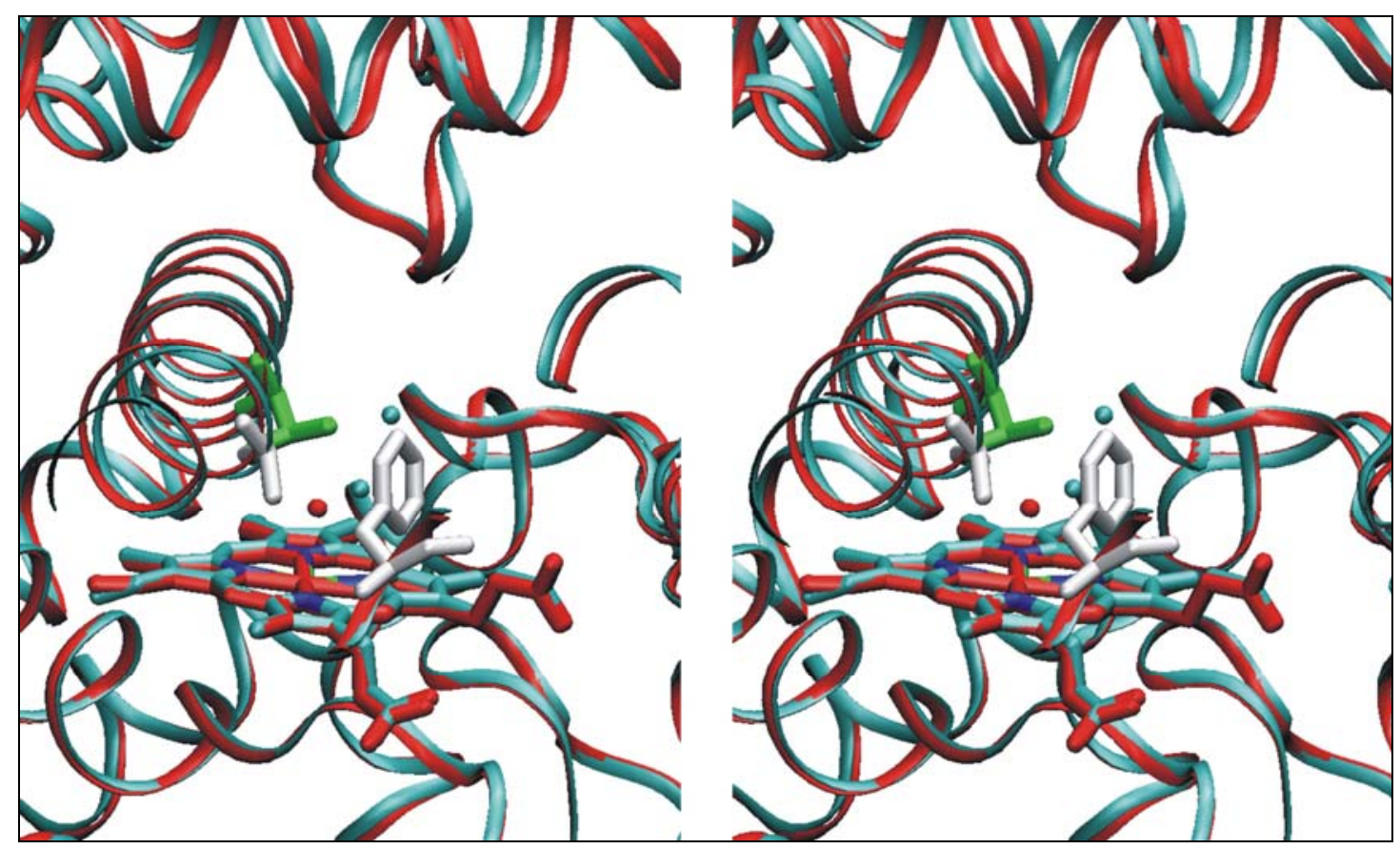

Figure S8: Stereo view of active sites of Lo-DMSO (cyan) and 1BU7 (red). Closest waters to the heme iron in Lo-DMSO are shown as cyan balls. Sixth water ligand in 1BU7 is shown as red ball. Picture is created using VMD. ${ }^{19}$

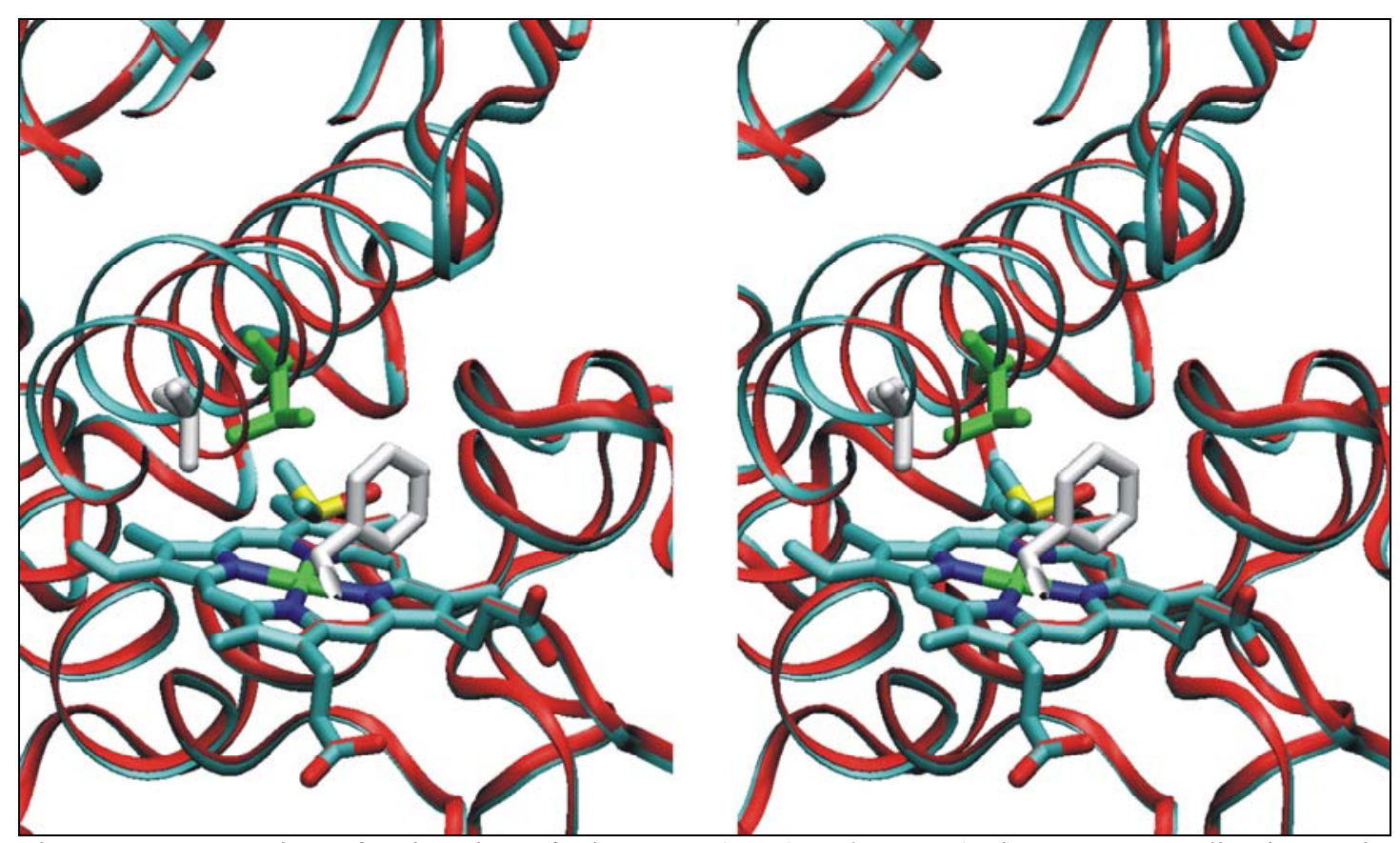

Figure S9: Stereo view of active sites of Hi-DMSO (cyan) and 1BU7 (red). DMSO coordinating to the heme iron in Hi-DMSO is shown in licorice. I-helix is bent more in Hi-DMSO, compared to that in 1BU7. Picture is created using VMD. ${ }^{19}$ 


\begin{tabular}{|lccc|}
\hline & Monomer A & Monomer B & Average \\
\hline Fe-S $_{\text {Cys400 }}$ & & & \\
1BU7 & $2.38 \AA$ & $2.27 \AA$ & $2.33 \AA$ \\
Lo-DMSO & $2.31 \AA$ & $2.28 \AA$ & $2.30 \AA$ \\
Hi-DMSO & $2.30 \AA$ & $2.31 \AA$ & $2.31 \AA$ \\
Fe-O & & \\
1 Water & & $2.69 \AA$ & $2.63 \AA$ \\
Lo-DMSO & $2.57 \AA$ & $3.97 \AA$ & $3.77 \AA$ \\
Hi-DMSO & $3.56 \AA$ & $\mathrm{N} / \mathrm{A}$ & $\mathrm{N} / \mathrm{A}$ \\
Fe-S & $\mathrm{N} / \mathrm{A}$ DMSO & $\mathrm{N} / \mathrm{A}$ & $\mathrm{N} / \mathrm{A}$ \\
1 BU7 & $\mathrm{N} / \mathrm{A}$ & $\mathrm{N} / \mathrm{A}$ & $\mathrm{N} / \mathrm{A}$ \\
Lo-DMSO & $\mathrm{N} / \mathrm{A}$ & $2.39 \AA$ & $2.37 \AA$ \\
Hi-DMSO & $2.35 \AA$ & & \\
\hline
\end{tabular}

Table S8: Summary of the heme coordination (distances between Fe and water/DMSO).

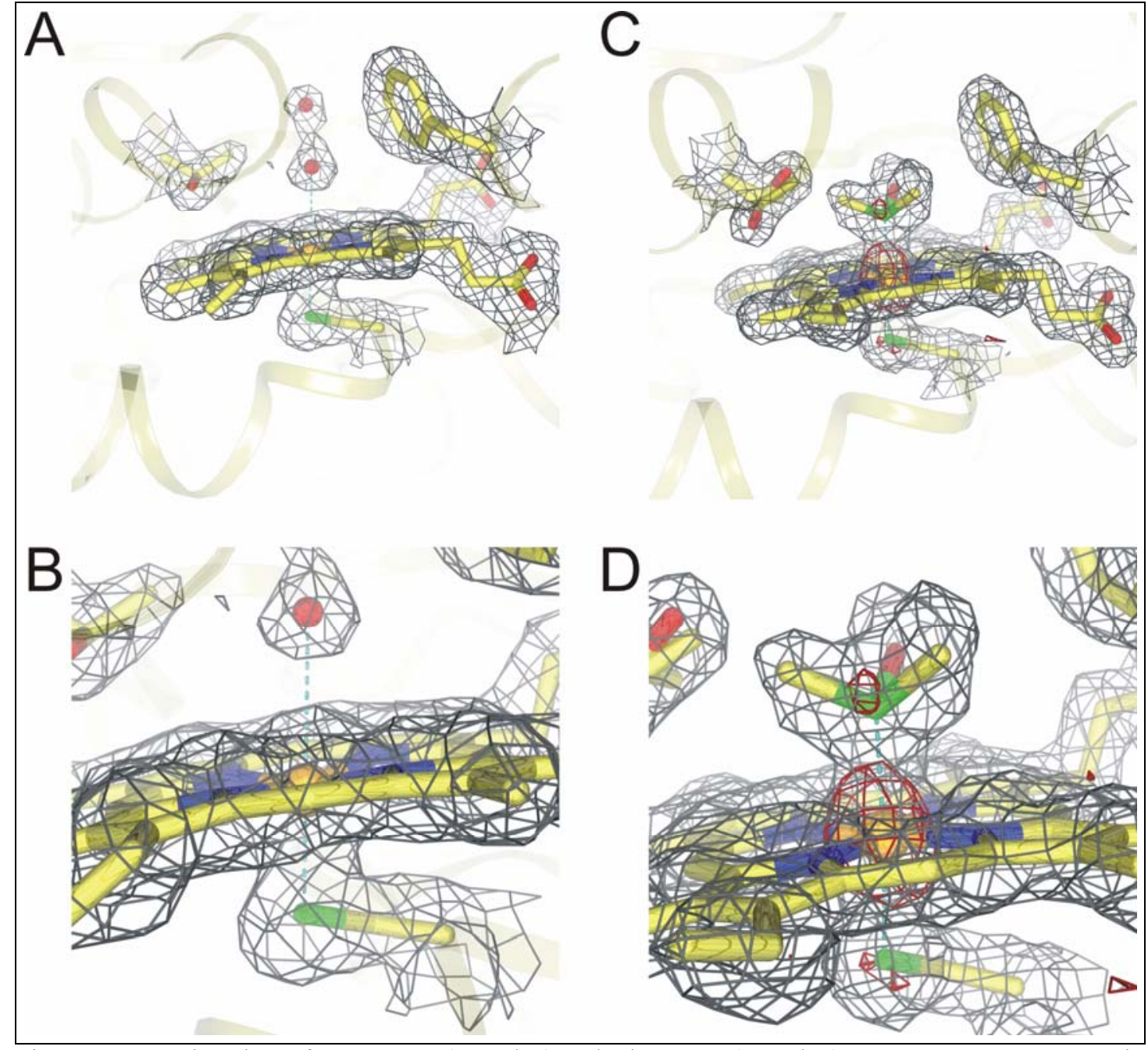

Figure S10: Active sites of Lo-DMSO (A and B) and Hi-DMSO (C and D). In Lo-DMSO, $\mathrm{H}_{2} \mathrm{O} 239$ is displaced aside from the heme iron. In Hi-DMSO, a DMSO molecule is coordinating to the heme iron via its sulfur atom. The orientation of DMSO is confirmed by anomalous scattering data (shown as red density). Figures were prepared with DINO (http://www.dino3d.org) and rendered with POVRAY (http://www.povray.org). 


\subsection{I-helix}

BMP's I-helix (D250-K282) contains a number of catalytically important residues, including A264 ${ }^{23}$ and T268 ${ }^{24-26}$. In the P450 reaction cycle, T268 provides proton for oxygen activation. ${ }^{24-26}$ Interestingly in Hi-DMSO monomer $\mathrm{B}$, two alternating conformations can be observed for residues H266-T268. In monomer A, alternating conformations can be found for T268. The I-helix in Hi-DMSO is bent to a larger degree compared to 1BU7 and Lo-DMSO (Figure S9, Table S9; RMSD of Hi-DMSO vs $1 \mathrm{BU} 7$ is $0.85 \AA$, RMSD of Lo-DMSO vs $1 \mathrm{BU} 7$ is $0.28 \AA$ ). Bending of the I-helix in Hi-DMSO could provide additional space to accommodate a DMSO molecule which is bulkier than a water molecule.

\begin{tabular}{|lccc|}
\hline 1BU7 & \multicolumn{3}{|c|}{ Lo-DMSO } \\
Monomer A & Monomer A & Monomer B \\
Monomer B & $0.33 \AA$ & $0.26 \AA$ \\
& $0.27 \AA$ & $0.27 \AA$ \\
\hline 1BU7 & & & \\
Monomer A & Honomer A & & Monomer B \\
Monomer B & $0.89 \AA$ & $0.82 \AA$ \\
& $0.89 \AA$ & & $0.81 \AA$ \\
\hline & & & \\
\hline Lo-DMSO & & Hi-DMSO & Monomer B \\
Monomer A & Monomer A & & $0.90 \AA$ \\
Monomer B & $1.00 \AA$ & & $0.86 \AA$ \\
\hline
\end{tabular}

Table S9: Root mean square deviations of I-helix, calculated for residues D251-K282 using GROMACS. ${ }^{18}$

\section{References}

1. Muchmore, D. C.; McIntosh, L. P.; Russell, C. B.; Anderson, D. E.; Dahlquist, F. W., Methods Enzymol. 1989, 177, 44-73.

2. Chung, C. T.; Niemela, S. L.; Miller, R. H., Proc. Natl. Acad. Sci. U. S. A. 1989, 86, 2172-5.

3. Omura, T.; Sato, R., J. Biol. Chem. 1964, 239, 2370-8.

4. Leslie, A. G., Acta Crystallogr. D. Biol. Crystallogr. 2006, 62, 48-57.

5. $\quad$ Evans, P. R., Joint CCP4 \& ESF-EAMCB Newslett 1997, 33, 22-4.

6. Acta Crystallogr. D. Biol. Crystallogr. 1994, 50, 760-3.

7. Read, R. J., Acta Crystallogr. D. Biol. Crystallogr. 2001, 57, 1373-82.

8. Sevrioukova, I. F.; Li, H.; Zhang, H.; Peterson, J. A.; Poulos, T. L., Proc. Natl. Acad. Sci. U. S. A. 1999, 96, 1863-8.

9. Emsley, P.; Cowtan, K., Acta Crystallogr. D. Biol. Crystallogr. 2004, 60, 2126-32.

10. Murshudov, G. N.; Vagin, A. A.; Dodson, E. J., Acta Crystallogr. D. Biol. Crystallogr. 1997, 53, 240-55.

11. Schwaneberg, U.; Sprauer, A.; Schmidt-Dannert, C.; Schmid, R. D., J. Chromatogr. A 1999, 848, 149-59.

12. Wong, T. S.; Wu, N.; Roccatano, D.; Zacharias, M.; Schwaneberg, U., J. Biomol. Screen. 2005, 10, 246-52.

13. Schwaneberg, U.; Otey, C.; Cirino, P. C.; Farinas, E.; Arnold, F. H., J. Biomol. Screen. 2001, 6, 111-7.

14. Schwaneberg, U.; Schmidt-Dannert, C.; Schmitt, J.; Schmid, R. D., Anal. Biochem. 1999, 269, 359-66. 
15. Wong, T. S.; Arnold, F. H.; Schwaneberg, U., Biotechnol. Bioeng. 2004, 85, 351-8.

16. Roccatano, D.; Wong, T. S.; Schwaneberg, U.; Zacharias, M., Biopolymers 2005, 78, 259-67.

17. Roccatano, D.; Wong, T. S.; Schwaneberg, U.; Zacharias, M., Biopolymers 2006, 83, 467-76.

18. Van Der Spoel, D.; Lindahl, E.; Hess, B.; Groenhof, G.; Mark, A. E.; Berendsen, H. J., J Comput Chem 2005, 26, 1701-18.

19. Humphrey, W.; Dalke, A.; Schulten, K., J. Mol. Graph. 1996, 14, 33-8, 27-8.

20. Noble, M. A.; Miles, C. S.; Chapman, S. K.; Lysek, D. A.; MacKay, A. C.; Reid, G. A.; Hanzlik, R. P.; Munro, A. W., Biochem. J. 1999, 339 ( Pt 2), 3719.

21. Li, H. Y.; Poulos, T. L., Biochimica Et Biophysica Acta-Molecular and Cell Biology of Lipids 1999, 1441, 141-9.

22. Ravichandran, K. G.; Boddupalli, S. S.; Hasemann, C. A.; Peterson, J. A.; Deisenhofer, J., Science 1993, 261, 731-6.

23. Joyce, M. G.; Girvan, H. M.; Munro, A. W.; Leys, D., J. Biol. Chem. 2004, 279, 23287-93.

24. Clark, J. P.; Miles, C. S.; Mowat, C. G.; Walkinshaw, M. D.; Reid, G. A.; Daff, S. N.; Chapman, S. K., J. Inorg. Biochem. 2006, 100, 1075-90.

25. Truan, G.; Peterson, J. A., Arch. Biochem. Biophys. 1998, 349, 53-64.

26. Yeom, H.; Sligar, S. G.; Li, H.; Poulos, T. L.; Fulco, A. J., Biochemistry (Mosc). 1995, 34, 14733-40. 